Send your letters to the Editor, British

Dental Journal, 64 Wimpole Street, London

W1G8YS E-mail bdj@bda.org

Priority will be given to letters less than 500

words long. Authors must sign the letter,

which may be edited for reasons of space.

\section{Biochemical abnormality}

Sir, we read with interest your recent article regarding a death following an odontogenic infection in a patient immunocompromised with chronic lymphocytic leukaemia (BDJ 2007; 203: 241-242). We wish to relay that it is our experience that deaths can still arise from odontogenic infections in Britain in the twenty-first century. Furthermore, patients need not be immunocomprised to succumb to airway obstruction or overwhelming sepsis.

We have had two deaths due to overwhelming dental sepsis in the last ten years, and up to 15 cases which we would regard as 'near misses'. ${ }^{1}$ The conditions arising from dental sepsis have included septic shock, necrotising fasciitis and airway obstruction. Common denominators included previous antibiotic use for dental infection without definitive dental treatment.

All dentists and doctors must be aware that antibiotic prescription is not a substitute for dental surgical control of infection, adhering to the principles of eliminating the source of infection, and drainage of pus.

In our experience, these patients often have at least minor abnormalities in liver function, often as consequence of excess alcohol consumption. ${ }^{2}$ We wonder if the patient reported by Carter and Lowis had any such biochemical abnormality.

\section{R. D. Molloy, G. C. S. Cousin \\ Blackburn}

1. Cousin G C S. Potentially fatal oro-facial infection: five cautionary tales. J R Coll Surg Edinb 2002; 47: 585-586.

2. Cousin G C S. Dying to get to the dentist. Presented at The British Association of Oral and Maxillofacial Surgeons Annual Scientific Meeting, Eastbourne 2006.

\section{DOI: DOI: 10.1038/bdj.2007.1117}

\section{Conflicting advice}

Sir, we read with interest the research paper by Dorman et al. (BDJ 2007; 202: E30) regarding the management of children undergoing surgical orthodontics with the aid of intravenous conscious sedation (IVCS). The authors should be congratulated on their drive to explore alternatives to general anaesthesia in children. Unfortunately the use of IVCS in children, as alluded to in the paper, is somewhat in conflict with GDC guidance $^{1}$ and we therefore feel its use should only be exercised with caution in a specialist unit with paediatric anaesthetic cover. We were disappointed that the paper largely dismissed the use of local anaesthetic alone.

In a recent retrospective audit in one of our satellite district general hospital units we performed surgical orthodontic procedures on 44 paediatric patients (age 12-16) over a three-year period. Twenty-five of these patients were willing to undergo the procedure under local analgesia (LA). Twenty of the LA procedures involved the exposure of palatal canines. All the patients had been initially assessed and then treated by the same specialist oral surgeon. Adequate time was given to discuss the procedure and answer any questions the child or parent had. LA was administered in a slow controlled manner with the adjunct of topical analgesia. The incisive block (where required) was initially introduced from the labial aspect via the interdental papilla and then completed via the orthodox palatal route significantly reducing patient discomfort. All the patients remained cooperative and tearless throughout. In most cases a parent remained in the room during the procedure. Only one procedure was abandoned due to incomplete analgesia. The successful outcome rate is in line with that stated in the paper by Dorman et al.

In conclusion we feel that a significant number of surgical orthodontic procedures can be safely and successfully performed under LA provided adequate explanation, time and atraumatic techniques are utilised.

T. Lord

I. Levisianos

Chester

1. Standing Dental Advisory Committee. Conscious sedation in the provision of dental care. London: Department of Health, 2003

DOI: DOI: 10.1038/bdj.2007.1118

\section{The KITS scheme}

Sir, C. D. Franklin (BDJ 2007; 203: 378) makes an understatement about SHAs 'needing persuasion' to release funding intended for the KITS scheme.

I was an active GDP with an NHS commitment until 2002, when a career break was forced upon me due to Dupytren's contracture. Initially, the Londonadministered KITS worked well. Costs for GDC membership, and for postgraduate study courses, were refunded. I was able to keep up-to-date and even to take a postgraduate diploma.

After delegation of the responsibility to the SHAs, however, the picture changed. I have been refused support by two neighbouring SHAs, leaving me with a difficult decision as to whether I can afford to retain my connections to the profession at all.

Practitioners who are on KITS will typically be enjoying a low income, yet are expected to keep up their GDC registration (a high price in itself, but also necessitating postgraduate study commitment with its own costs), BDA membership and defence organisation membership.

We are occasionally reminded how much it costs to train a new dental graduate - how much more must a competent and experienced practitioner be worth?

The mechanisms for support are supposedly in place. Why is it so difficult to get it?

D. G. Watt

By email

DOI: DOI: 10.1038/bdj.2007.1119

\section{Bite relief}

Sir, my dentist has just 'refilled' a molar because some of the filling had broken away. Naturally, he injected the necessary painkiller which deadened the surrounding tissue. The job was done and home I went.

However, when the effects of the novocaine (?) had worn off I had the problem of crunched tissue looking like a large ulcer. Every time I eat and no matter how careful I am my teeth in that area keeping biting the swollen 
area. As it is now 2007, I would have thought that some wise dentist/technician would have invented a simple piece of material (like polythene) shaped appropriately to slot into the fleshy area at the side of the teeth to save you from biting yourself during the four hours after treatment when the damage occurs. Allowing for health and safety issues is there anyone in the dental field who has the desire to progress this? In my case I cut a piece of celluloid into the shape of a large crown piece and stuck that alongside my molars to give me some relief, but it would have been more efficacious if there was something cheap and designed for the purpose and which could be thrown away after the four hours.

\section{E. N. Vaughan}

Leighton Buzzard

DOI: DOI: 10.1038/bdj.2007.1120

\section{Root treatment}

Sir, as a Garden Steward at the National Trust's Sheffield Park Garden I was asked to guide members of the International Dendrological Society. Able to answer the first question from these tree experts I told the group that I was no plant expert, merely knowledgeable on the planting at the property. Telling them that before retirement I was a dentist the rejoinder from Tony Kirkam of Kew was that we were in the same business! They extract, fill holes and do root treatment. My question as to whether they sterilised their tools after use produced laughter. I wonder if patients in search of a dentist might ask in future for a dendrologist rather than an odontologist?

\section{P. Erridge}

East Grinstead

Editor-in-chief's note: Readers may have similar suggestions for the descriptions of other occupations that might use related terminology? Crowns in foreign currency dealing, or conservation of enamel in plumbing for example? Please send us your thoughts.

DOI: DOI: 10.1038/bdj.2007.1121

\section{Nit-picky comments}

Sir, working as an endodontic specialist in my home town, where I know and respect many general dental practitioners, I am frequently asked to comment on the current 'prion fiasco'. I have abundant sympathy for the $\mathrm{NH}$ dentist who is advised to dispose of all his endodontic files after every endodontic procedure, given that the current perceived wisdom seems to be a minefield of disinformation. The paper
Cleanability of dental instruments (BDJ 2007; 203: 395-401) is a good example. It shows a photograph of an endodontic barbed broach with attached pulp. The photograph is titled 'endodontic file' which it patently is not, the significance being that the barbed broach shown would go straight in the sharps bin. This is just the sort of ongoing confusion and poor 'reporting' that is so worrying at the actual practice, operative level.

I beg the question: who are the authors and what were they thinking and even more importantly what were the referees thinking about?

These comments might sound nitpicky but I think they reflect the actual practical concern we all share at this troubled time.

\section{Emery \\ Portsmouth \\ DOI: DOI: 10.1038/bdj.2007.1122}

\section{Aspirational CDs}

Sir, I enjoyed the article by Drs Richards and Toy (BDJ 2007; 203: 453-455) and the issues they raised about bringing aspirational policy into real life. I noted that the article was accepted in May 2007, and wondered if any readers had not received the CD-Rom referred to in the article, which was sent out earlier this year. There are still a fair number of copies left, and if any readers wish a copy, if they email their name and address to me at nigel.thomas@rotherhampct.nhs.uk, I will arrange to send one out until they have all gone.

N. Thomas

Rotherham PCT

DOI: DOI: 10.1038/bdj.2007.1123

\section{Shisha confusion}

Sir, I am referring to Dr Bhat's interesting alert on hookah (shisha, narghile) potential hazards. ${ }^{1}$ The expressed concerns are largely based on two cited studies (Gatrad et al. 2007; Maziak et al. 2004). Regrettably, both of them are confusing. Some misrepresentations in the first one have been reported. ${ }^{2}$ As for the other, it is not empty of serious errors. One of them - and this is important because Dr Bhat discusses cancer issues - is to credit Rakower and Fatal with exactly the opposite of what they stated in their famous historical study about narghile and lung cancer. ${ }^{3}$

This said, I would also like to correct the misuse of the word 'shisha'. The latter does not refer to tobamel/mu'essel* but the pipe itself. Indeed, shisha happened to be the modern contemporaneous version of the traditional hookah and is particularly adapted for the above smoking product. 
The word 'burning' is not adequate when referring to a shisha with tobamel because the latter is, to a great extent, only heated (chemical reaction akin to the Maillard one). ${ }^{4}$ However, it may be charred in certain adverse conditions (misuse, smoking machine, etc). Consequently, a prevention message for those who have decided not to quit immediately could be: avoid smoking until the coal chars the tobamel. Move the coal around atop the hookah bowl or leave it. Otherwise, you might well inhale hazardous toxicants (such as PAH) generated by session-end combustion.

If, in the tobamel configuration, the mild smoke is directly inhaled in the lungs with no previous stocking in the mouth (as with cigarettes), it is above all because notorious irritants are efficiently filtered: among them aldehydes. ${ }^{4}$ In fact, the main and clearly identified problem is the carbon monoxide generated by the glowing charcoal, particularly in ill-ventilated places. Unfortunately, despite early warnings on this topic, public health agencies are procrastinating the urgent analysis of the unknown exact chemical composition of the widely used quick-lighting charcoal (formerly used to burn incense) that took the place of the natural 'traditional' one.

Certainly hookah smoking is not an innocent habit like other 'recreational' tobacco use modes (cigar, short 'dry' pipe). However, we public health practitioners should tackle this highly complex issue with extreme caution. The worlds of cigarette and hookah smoking are very different from each other. Analytical or prevention models cannot be superimposed so easily.

\section{K. T. Chaouachi}

Researcher and Consultant

in Tobacco Control (Paris)

Teacher of a Comprehensive Course

on Hookah (Narghile, Shisha)

Smoking for French Doctors

*The tobacco [or no-tobacco]-molasses based smoking mixture. Its name is actually mu'essel in formal Arabic (meaning 'honeyed', rendered by 'mel' in Latin), sometimes transliterated mo'assel or ma'assel according to local pronunciations.

1. Bhat M. Hookah hazards. Br Dent J 2007; 203: 441

2. Chaouachi K. [Rapid Response] Hookah smoking: a few comments on some errors and misconceptions. Br Med J 2007; 335: 20.

3. Rakower J, Fatal B. Study of narghile smoking in relation to cancer of the lung. Br J Cancer 1962; 16: 1-6.

4. Chaouachi K. Re: Tobacco smoking and periodontal health in a Saudi Arabian population. J Periodontol 2006; 77: 929-930.

DOI: DOI: 10.1038/bdj.2007.1124

\section{Paediatric consent}

Sir, I write to draw readers' attention to some issues raised by a recent publication regarding consent for paediatric surgery. ${ }^{1}$ The prospective study based at Southampton General Hospital involved adults consenting for 100 children due to have elective or emergency surgery under general anaesthetic. The adults were questioned about the possession of parental responsibility and their understanding of the concept on returning from the operating theatre.

The study found that in $4 \%$ of the cases, the consent was invalid. In those cases, the consent form had been signed by unmarried fathers, none of whom had acquired parental responsibility. The attitudes towards consent were perhaps surprising. Of the adults, $82 \%$ thought that cohabitation was a sufficient qualification to provide consent. Less than 15\% recognised marital status as being relevant.

It seems that valid consent is often gained by luck rather than by judgement since natural mothers are often the adult to present with the child in the healthcare setting (75\% of cases in this study).

In general dental practice, consent is given verbally the majority of the time. However, the same principles regarding the validity of the consent still apply as for written consent. ${ }^{2}$ When agreeing treatment plans in which irreversible procedures such as tooth extraction are planned, one must be particularly careful about obtaining valid consent. Only adults with parental responsibility (PR) can provide valid consent for an 'incompetent' child. ${ }^{1}$

Picture the scenario whereby an unmarried father presents with a child and extraction is indicated. It is likely the father fully believes he has the legal right to give consent for his child. The problem for the dentist is that if they perform an extraction on a child with invalid consent, legally the child has been assaulted. One could say 'what does it matter' if everyone is acting in the best interests of the child? A lawyer might not take such a relaxed view should any complications arise.

This is a problem area that should diminish with time. Unmarried fathers of children born after December 2003 automatically obtain parental responsibility (PR) if their name is registered on the birth certificate. ${ }^{3}$ For unmarried fathers of children born before this date, PR can be obtained with the consent of the court by a very simple and inexpensive procedure. ${ }^{1}$

The study ${ }^{1}$ concludes that there is a wide gulf between the standards set by the Children Act $1989^{4}$ and common practice. It certainly made me consider perhaps one should place just a fraction more attention to who exactly is accompanying a child and whether they truly have parental responsibility.

\section{A. J. Barber \\ H. Zaitoun \\ Liverpool}

1. Elmalik K, Wheeler R A. Consent: luck or low? Ann $R$ Coll Surg Eng/ 2007; 89: 627-630.

2. Good practice in consent implementation guide: consent to examination or treatment. Department of Health, November 2001.

3. Adoption and Children Act 2002, Part 2, 111 Amendments of the Children Act, 1989.

4. Children Act 1989.

DOI: DOI: $10.1038 /$ bdj.2007.1125

\section{Open wider}

Sir, as the scope of dental practice expands into the offering of Botox and dermal fillers, we should rejoice in a new technique reported today (15 November) in the prestigious Spanish daily, El Pais. Surgeons in Barcelona describe a jaw-dropping case of endoscopic gall bladder removal through the mouth, with surgical access down the oesophagus via a $2 \mathrm{~mm}$ exit incision in the stomach into the abdominal cavity.

Heretofore I might have proudly exhibited the delivery of a four-rooted upper molar with all apices intact, small beer compared with the flourish of a tangerine-sized gall bladder replete with stones.

Dr Antonio M. deLacy concludes with the hope of similarly utilising other nether-body orifices. With such advances, can the six-month 'cheek-up' be far behind?

I. P. Hunter

Spain

DOI: DOI: 10.1038/bdj.2007.1126 